\title{
2006-730: USING WIRELESS TABLET PERSONAL COMPUTERS TO EXTEND ENGINEERING TECHNOLOGY CLASSROOMS AND ENHANCE LEARNING
}

\section{Lisa Jones, Southwest Tennessee Community College}

Lisa G. Jones is currently Assistant Professor in Electrical Engineering Technology at Southwest Tennessee Community College in Memphis, Tennessee. She joined Southwest in 2002 after 20 years of working as a design engineer and project manager in the electronics industry including Bell Labs, AT\&T, Truevision, and Thomson Consumer Electronics. Ms. Jones earned her BSEE degree from Memphis State University in 1980 and her MSEE degree from Georgia Institute of Technology in 1981.

\section{James M. Northern, Southwest Tennessee Community College}

James M. Northern, P.E., is currently Program Coordinator of Electrical Engineering Technology at Southwest Tennessee Community College. He graduated from Memphis State University with a B.S. in Electrical Engineering in 1970. He also has a B.S. in Psychology and a M.S. in Technical Education from Memphis State University. Mr. Northern worked as an engineer and senior engineer at Allan \& Hoshall for 8 years in the area of rural power system analysis and has been teaching at Southwest for 25 years in the areas of instrumentation and electrical engineering technology. 


\section{Using Wireless Tablet Personal Computers to Extend Engineering Technology Classrooms and Enhance Learning}

\section{Introduction}

The Engineering Technology Department is using wireless tablet PCs to expand its just-in-time education initiative, dual credit program with high schools, and its one year technical certificate programs. The department is using the wireless tablets and classroom management software to enhance classroom technology on various under-served off-campus locations. By incorporating them into its courses, the department is able to create distance education courses and improve teaching methods. To take advantage of the power of the tablet PCs, classroom presentations are converted to PowerPoint presentations and more problem-based case studies that support critical thinking, interactive learning, and team/peer instruction are added. The Engineering Technology curriculum has many problem-based courses and laboratory exercises that can be used to support active and collaborative learning while using the wireless tablet PC.

The wireless capability of the tablets allows for the quick conversion of a regular classroom to a computer lab. All that is required is the wireless tablets and an access point connected to the Internet if Internet access is desired. The instructor can use the tablet PC and projector to make presentations. Using the pen input, the instructor can easily annotate PowerPoint slides during the presentation and can create and solve new problems in real time. The tablet PC and projector eliminate the need for a blackboard. Having the flexibility to teach courses with minimal facilities allows the Engineering Technology Department to move its classrooms to appropriate off-campus sites near the students.

\section{Rationale}

Historically the Engineering Technology programs have been available only at the main technology campus. Students knew what field they were interested in, were very mature, working, and advancing their careers. To attract more students, the Engineering Technology Department has developed a just-in-time initiative. The department is offering a seamless education that starts with a technical certificate and progresses to an associate's degree and beyond. The department is developing the capability to offer the certificate programs at locations throughout the local area, including the urban campus. As the course offerings expand, the student population consists of a broader range of students with multiple commitments and a wider range of socioeconomic circumstances. To keep these students interested, the department is incorporating new technology and teaching methods.

The new technology and teaching methods also support the Engineering Technology Department's commitment to accreditation and employers. Its graduates must be able to apply creativity to the solution of problems and effectively communicate their solutions orally and in writing. Using the tablet PC and adding more problem solving exercises and presentations to the courses help develop those skills. Figure 1 shows students collaboratively working on a problem. Figure 2 shows one of the student's classroom presentations. Wireless tablet PCs are a 
significant contributor to enabling the Engineering Technology Department's ability to provide a quality education to its students and achieving its commitments and educational outcomes.

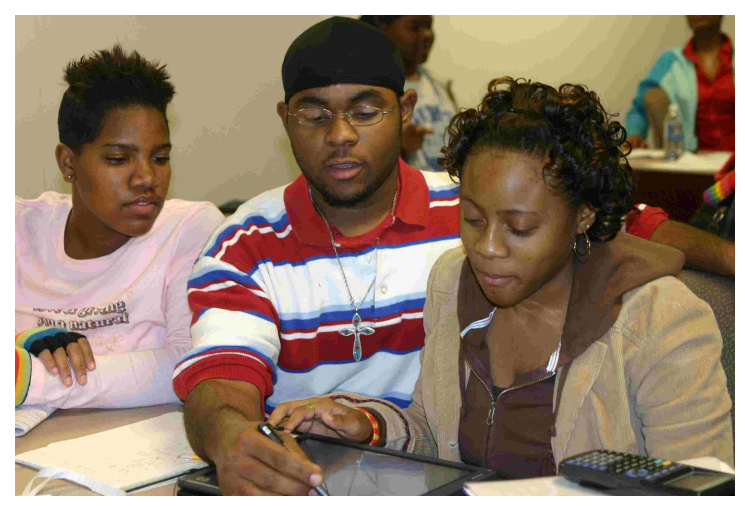

Figure 1. Students collaborating on a problem.

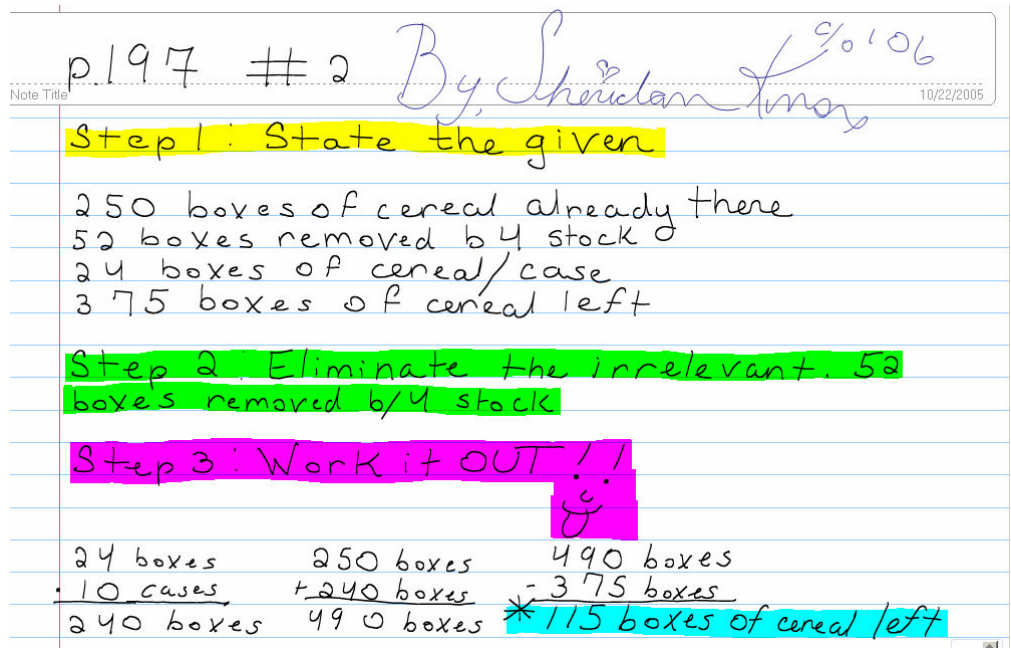

Figure 2. An example of a student presentation.

Research demonstrates the ability of tablet PCs to improve teaching and learning at all levels of education. K-12 schools across the country are using technology to improve education and the results are extremely positive. Teachers report that they get more done in less time and that faculty and student excitement with tablet PCs is contagious. ${ }^{1,2}$ Figure 3 shows two students celebrating the successful completion of their assignment. Students are learning how to think instead of what to think and reaching deeper into learning and understanding. Struggle and frustration are no longer evident and there are significant gains in writing and problem-solving. ${ }^{1,2}$ All of these achievements are required by faculty and students. 


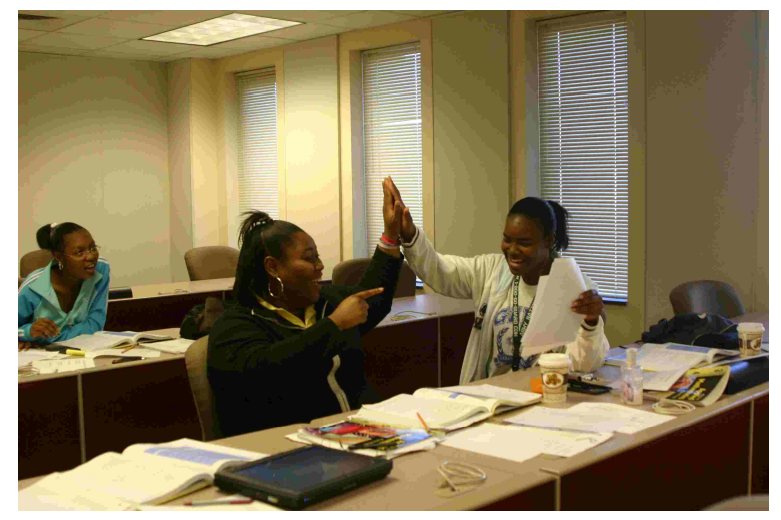

Figure 3. Problem solved!

At the high school level, equal opportunity for an "ever-modernizing, ever-mobile student body"3 has been achieved by the use of technology, especially tablet PCs. With a tablet PC, every desk becomes a front row seat and a student missing class and students with handicaps have complete internet access to notes, presentations, and assignments. ${ }^{3}$

At the college level, research shows great potential for improved learning and teaching in computer related curriculums. The inherent capability of tablet PC digital ink supports visual learning. ${ }^{4}$ Tablet PCs can be applied to information worker tasks in an education environment. ${ }^{5}$ The tablet PC also promises to improve active and collaborative learning in computer science courses. ${ }^{6}$ The Engineering Technology Department's goal is to transfer the success found in the computer fields to the engineering technology curriculum.

\section{Impact on Teaching}

Prior to the incorporation of wireless tablet PCs, the courses were chalk and talk. To take advantage of the technology of the tablet PC, classroom presentations were converted to PowerPoint presentations. The presentations were given using a tablet $\mathrm{PC}$ and digital projector on the urban campus. The instructors use the PowerPoint presentations and add digital ink examples and extra content. The tablet PC allows the department to expand its classroom to both its urban campus and outlying suburban campuses. The use of the tablet PC and classroom management software allows the department to teach one course with one instructor to two different locations at the same time. Communications between the instructor and the remote students is via the classroom management software and a video and audio link.

\section{Conclusion}

The use of the wireless tablet enhances the learning activities in the classroom. The digital ink capability of the tablet PCs enables the students to generate presentations with little effort compared to a desktop PC with the standard mouse or pencil and paper. The students embrace the technology quickly and become power users within minutes. They enjoy creating and presenting their solutions to the class. A competition between the students often develops as to who can give the most creative presentation. In the classes without the tablet PC, the students lack the enthusiasm of the tablet PC users especially when solving and presenting their problems. 
The Engineering Technology Department expects to continue to see general improvements in enthusiasm with course work and a greater commitment to learning and class participation as a result of applying tablet PC technology to its courses. In particular, the department is anticipating continued improvements in problem solving and presentation skills. Using wireless tablet PCs allows the department to extend its classrooms to the students as distance learning courses and to enhance the learning process by allowing the use of unique techniques.

\section{Acknowledgement}

The authors would like to thank Hewlett-Packard for the HP Technology for Teaching Grant which provided the wireless tablets used in this study.

\section{Bibliography}

[1] "Looking at the Freedom to Learn program through different lenses. (1 to 1 Computing)." T.H.E. Journal (Technological Horizons In Education) 32.8 (March 2005): S1(2).

[2] Harless, S. \& Harthun-Reed, A. "Laptop initiative creates equal educational opportunities. (Case study: Bear Lake Middle School)." T.H.E. Journal (Technological Horizons In Education) 32.8 (March 2005): S6(1).

[3] Barton, C. \& Collura, K. "Catalyst for change (Feature)." T.H.E. Journal (Technological Horizons In Education) 31.4 (Nov 2003): NA(6).

[4] Willis, C. \& Miertschin, S. "Mind Tools for Enhancing Thinking and Learning Skills." Proceedings of the 6th conference on Information technology education. Association for Computing Machinery (ACM). SIGITE (2005). Available at http://portal.acm.org. Accessed January 7, 2006.

[5] Willis, C. \& Miertschin, S. "Tablet PC's as Instructional Tools or the Pen is Mightier than the 'Board!" Proceedings of the 5th conference on Information technology education. Association for Computing Machinery (ACM) (2004). Available at http://portal.acm.org. Accessed January 7, 2006.

[6] Simon, B., Anderson, R., Hoyer, C., \& Su, J. "Preliminary Experiences with a Tablet PC Based System to Support Active Learning in Computer Science Courses". Proceedings of the 9th annual SIGCSE conference on Innovation and technology in computer science education. Association for Computing Machinery (ACM) (2004). Available at http://portal.acm.org. Accessed January 7, 2006. 